\title{
Charting the Growth of Canada's Aboriginal Populations: Problems, Options and Implications
}

\section{Eric Guimond}

Indian and Northern Affairs Canada

Ottawa, Ontario

\section{Don Kerr,}

Roderic Beaujot,

University of Western Ontario

London, Ontario

\begin{abstract}
Toward the end of the $20^{\text {th }}$ century, the number of persons reporting Aboriginal ancestry in the Canadian Census increased in a rather dramatic manner. For example, in the 2001 Canadian Census, over 1.3 million Canadians reported an Aboriginal origin, which is an increase of about 20 percent over the previous census in 1996. Given that much confusion and inadequate information characterises public discussions of the demographics of Canada's Aboriginal population, this paper will review the most fundamental data sources and definitions that have been used in documenting the characteristics of this population, as well as outline some of the most important obstacles to be faced in enacting meaningful quantitative research in this context.
\end{abstract}

Key Words: Aboriginal population, aboriginal ancestry, 
Eric Guimond, Don Kerr and Roderic Beaujot

\section{Résumé}

Vers la fin du $\mathrm{XX}^{\mathrm{e}}$ siècle, le nombre de personnes faisant état d'un héritage autochtone au recensement canadien avait énormément augmenté. Par exemple, dans le recensement de 2001, plus de 1,3 million de Canadiens signalaient une origine autochtone, ce qui représente une augmentation de 20 pour cent par rapport au recensement précédent de 1996. Compte tenu du fait que les discussions publiques sur les aspects démographiques des peuples autochtones du Canada font toujours l'objet de beaucoup de confusion et d'information incorrecte, cet article examine les sources de données et de définitions les plus fondamentales qui ont servi à documenter les caractéristiques de cette population tout en donnant les grandes lignes des principaux obstacles à considérer pour faire des recherches quantitatives utiles dans ce domaine.

Mots-clés : peuples autochtones, héritage autochtone, identité autochtone, Inscription des Indiens

\section{Introduction}

In the epilogue to her comprehensive volume on the history of Canada's First Nations, Dickason (2002) points to what she considers the most prominent theme to characterise the history of Aboriginal peoples in Canada. More specifically, in a context of what was far too often forced assimilation and marginalization, Dickason emphasises "the persistence of Amerindian tradition and identity" (2002:419). In contrast to what she identifies as the popular European myth of "Indians as a vanishing people," she forcefully argues that Aboriginal culture in Canada continues to maintain considerably vitality. For example, Dickason points out that a growing proportion of Canadians with Aboriginal ancestry appear to be showing considerable interest and "selfidentification" with their cultural traditions and history.

In this context, social scientists in both the United States and Canada have documented phenomenal growth in the number of persons reporting Aboriginal origins over recent censuses. In the 2001 Canadian Census, over 1.3 million Canadians reported an Aboriginal origin, which is an increase of about 20 percent since the 1996 Census. In hearing of this increase, the typical reaction on the part of the Canadian media has been to highlight the relatively high birth rate of the Aboriginal population as well as its relatively young age profile (Globe and Mail, 2003). Yet in actual fact, this growth is many times greater than what could have occurred merely due to high fertility (Guimond, 1999). 
Of importance in this regard is the simple observation that respondents to the Canadian Census are often far from consistent in the manner in which they report on cultural origins or ancestry (Boyd and Norris, 1999). This problem is not limited to the Aboriginal population. Observing the fluidity of the data, Ryder (1955) had proposed that the Canadian Census stop collecting data on ethnic origins. These problems have been accentuated through the open invitation to declare multiple ethnic origins, and even to use "Canadian" as an ethnic origin. There is clearly considerable uncertainty in charting past and future change in the ethnic composition of the Canadian population. While one might expect this uncertainty to be of utmost importance to anyone engaged in social research and/or social planning on Aboriginal peoples in Canada, it is surprising how little attention this fluidity in ethnic self-reporting has received. Given that much confusion and inadequate information characterises most discussions of the demographics of Canada's Aboriginal populations, this paper will review some of these issues, including some of the most serious methodological and data quality problems that serve to hinder meaningful quantitative research on Canada's Aboriginal population.

\section{Definitional Issues}

Most attempts at population estimation and in documenting population change focus on the nation state or on populations as defined in terms of political boundaries and place of residence. Consequently, the definition of who is to be included in the target population of any analysis is usually straightforward, as defined by rules relating to citizenship or usual place of residence. Yet in the study of Aboriginal populations, or for that matter, any group defined in terms of cultural or ethnic affiliation, the issue of defining exactly who is to be included becomes much more complicated.

The next few sections of this paper will specifically address some of these issues. This will be done by broadly sketching how the Canadian census has defined Canada's Aboriginal population. The concepts and data available in studying the demography of Aboriginal peoples are far from being straight forward, and in essence, reflects definitions as developed by government officials and researchers (Goldmann, 1993; Goldmann and Siggner, 1995). It is in this context that census enumerators have documented phenomenal growth in the size of the Aboriginal populations over the latter $20^{\text {th }}$ century. Yet depending upon how the Aboriginal populations are delineated, very different conclusions might be drawn as the dynamics of this growth and the corresponding demographic characteristics of these populations. 


\section{Defining Aboriginal Populations on the Basis of Ancestry}

At one point in Canada's history, this issue of delineating the Aboriginal populations of Canada for demographic/quantitative analysis might have been a relatively straightforward matter, i.e. the Aboriginal populations could be defined easily in terms of culture, genealogy and geography. While a high level of variability characterised Aboriginal language, values, social roles and material culture - there were certain cultural and genealogical elements of commonality that facilitated the identification of Aboriginal persons. Yet in contrast to the situation historically, the situation currently has become far more complicated - due to the simple fact that we have witnessed several centuries of acculturation, intermarriage and migration. While it might have been relatively obvious to the $17^{\text {th }}$ or $18^{\text {th }}$ century observer as to who was Mi'kmaq or Mohawk, as opposed to British or French, currently it is often far from being the case. As a result, many researchers have merely relied upon information as collected through the Canadian census in classifying persons into one of the following categories - North American Indians (registered or not), Métis or Inuit.

The Canadian census is the most comprehensive source of demographic data on Aboriginal peoples in Canada, and is the exclusive source of demographic data for many Aboriginal groups. Since 1891, the Canadian census has provided counts of the Aboriginal populations in Canada by asking respondents about their ethnic origin (Goldmann, 1993). For example in the 2001 Census Canadians were asked as "To which ethnic or cultural group(s) did this person's ancestors belong?" - while encouraging respondents to report as many origins that they deem appropriate (Statistics Canada, 2002). Whereas some respondents have responded to this item by being rather specific in their response (e.g., Objiway, Mohawk, Nuu'chah'nulth"), others have provided less detail (e.g., North American Indian).

While the Canadian census data on ethnic origin is perhaps the most comprehensive set of demographic data on Aboriginal populations, this is not to deny that there are an assortment of difficulties that are typically encountered in working with this information (White et al., 1993; Kralt, 1990; Demers, 1979). One of these problems relates to the issue of data comparability over time. With a reliance upon the ethnic or cultural origin item in distinguishing Aboriginal persons from other Canadians, there have been frequent changes in terms of the wording and definitions involved (Goldmann, 1993). As an example, prior to the 1986 Census, multiple responses on the ethnic origin item were either disallowed (before 1981), or at the very least, not actively encouraged (1981), a situation that was completely reversed from 1986 onwards. 
Charting the Growth of Canada's Aboriginal Populations: Problems, Options and Implications

The encouragement of multiple origins has lead to more people reporting Aboriginal ancestry - relative to a situation whereby multiple or matrilineal origins were neglected. As demonstrated in Figure 1, the number of persons reporting Aboriginal ancestry has increased in a rather dramatic manner over recent years - as only 491,465 persons reported Aboriginal ancestry in 1981, far below the 1,319,890 recorded in 2001 - only 20 years later. In a period of only two decades, the size of this "ancestry based" population skyrocketed by almost $170 \%$. Underlying this change was an increase in the number of persons who reported Aboriginal ancestry as part of a multiple response, increasing from only 78,085 persons in 1981 to 754,845 persons in 2001. As Canada's population overall increased by $25 \%$ over this same period, the growth of the Aboriginal ancestry populations of Canada was obviously far beyond expectations, i.e. far beyond what might have been expected on the basis of natural increase (births minus deaths).

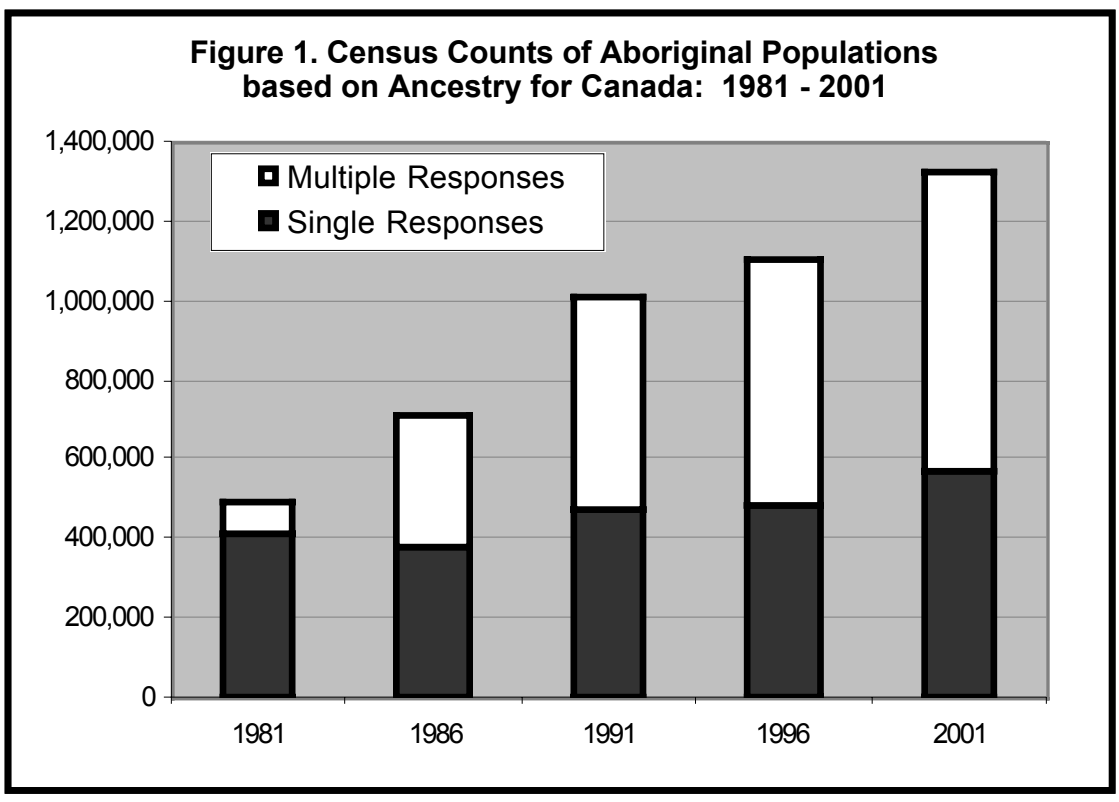

Sources: Statistics Canada, 1981 to 2001 Censuses of Canada. 
Whereas the encouragement of multiple responses has clearly had its impact on the size of Canada's Aboriginal ancestry populations, it would certainly be in error to suggest that all such growth was merely the result of this change in census methodology. For example, in comparing responses across the 1996 and 2001 Censuses with a very similar wording on the ethnic origin question across the two censuses, the reporting of Aboriginal ancestry increased both as a "single response" (18\%) as well as part of a "multiple response" (21\%).

\section{From Aboriginal Ancestry to Aboriginal Identity}

As mentioned earlier, a reliance upon "ancestry" in defining the Aboriginal population of Canada provides for a total population count of 1,319,890 persons in 2001 (or about $4.4 \%$ of Canada's population). This is not an insignificant number, as this total population count actually surpasses in size all but four of Canada's thirteen provinces and territories. Yet at the same time, some researchers have criticised the use of ancestry in the delineation of Canada's Aboriginal population, as being overly ambiguous and in some ways misleading (Romaniuc, 2000; Krotki, 1995). Whereas we can attempt to document through the census the total number of persons with Aboriginal ancestry, this tells us nothing about the degree to which an individual might actually feel "Aboriginal" or identify with "Aboriginal culture".

Efforts to establish time series data on Aboriginal populations will always be hindered by the "fluid or situational character" of such concepts as ancestry or cultural origins (Boxhill, 1984; Lieberson and Waters, 1993). Persons of Aboriginal ancestry may deny their origins, others may have a passionate commitment to these origins, while others still, may be somewhat passive, indifferent or simply unaware. In light of some of these difficulties, in 1996 Statistics Canada decided to introduce a new item into the Canadian census (beyond the ethnic origin question) with the ultimate goal of improving upon the enumeration of Canada's Aboriginal populations. In recognition of the fact that Aboriginal ancestry does not necessarily imply identification with Aboriginal culture, the 1996 Census included a new question that asked in a straight forward manner "Is this person an Aboriginal person, that is, North American Indian, Métis or Inuit (Eskimo) ?" The raison d'etre of this item was to more carefully determine whether or not individuals feel an allegiance or association with Aboriginal culture, beyond reporting Aboriginal ancestry.

In working with this "Aboriginal identity item," results from the 2001 Census indicate that 976,305 persons identified themselves as Aboriginal (Table 1). Defined in this manner, Canada's Aboriginal population drops from its original $4.4 \%$ of Canada's total population to $3.3 \%$. North American Indians form the 
Charting the Growth of Canada's Aboriginal Populations:

Problems, Options and Implications

largest Aboriginal identity population $(62.4 \%$, or 608,850 ), while 292,310

Canadians reported a single Métis identity in 2001. In addition, 45,070 persons self-reported a single Inuit identity.

Table 1

Size and growth of the Aboriginal identity populations for Canada: 1996 - 2001

\begin{tabular}{lccc}
\hline \multicolumn{1}{c}{ Aboriginal Identity } & $\mathbf{1 9 9 6}$ & $\mathbf{2 0 0 1}$ & $\begin{array}{c}\text { Percent Change } \\
\mathbf{1 9 9 6 - 2 0 0 1}\end{array}$ \\
\hline Total & 799,010 & 976,305 & 22.2 \\
North American Indian & 529,040 & 608,850 & 15.1 \\
Métis & 204,115 & 292,310 & 43.2 \\
Inuit & 40,220 & 45,070 & 12.1 \\
$\begin{array}{l}\text { Multiple and Other } \\
\text { Aboriginal Responses }\end{array}$ & 25,640 & 30,080 & 17.3 \\
\hline
\end{tabular}

Note: Includes persons who reported more than one Aboriginal identity group (North American Indian, Métis or Inuit) and those who reported being a registered Indian and/or Band member without reporting an Aboriginal identity. A sizeable proportion of the above Aboriginal identity population also report mixed ancestry on the ethnicity item of the census, including non-Aboriginal origins.

Source: Statistics Canada, 2003.

The term North American Indian is a broad "ethnocultural label" that groups individuals of some 60 different First Nations. While not presented in Table 1, it is noted that less than half $(44.7 \%)$ of the North American Indian identity population lived on an Indian reserve ${ }^{1}$ in 2001 . The term Inuit has come to 
Eric Guimond, Don Kerr and Roderic Beaujot

gradually replace the label "Eskimo" in the common lexicon of Canadians, largely due to the insistence on the part of the Inuit themselves to use the more appropriate Inuktitut word. The word Métis has two different meanings in Canada: it has been used to denote any person of mixed Indian and European ancestry ("métis" just means "mixed" in French"), yet perhaps more commonly, Métis is used to denote a hybrid culture that developed primarily in Western Canada in the $18^{\text {th }}$ and $19^{\text {th }}$ centuries (Dickason, 1992). The Métis culture cannot be associated with any specific language or ethnic origin - it is rather a cultural, linguistic and territorial mosaic with which a population has identified and developed an original culture. The sense of belonging to this culture has varied over time and in response to political and social events.

In addition to the ancestry and identity items in the Canadian Census, Statistics Canada also collects information on Aboriginal languages via the census items on home language and mother tongue. While this information is of great value to researchers, and in particular, to Aboriginal organizations in the promotion of Aboriginal culture, only a minority of Aboriginal peoples in Canada report an Aboriginal language. For example, according to the 2001 Census, a total of 235,075 individuals, or about one-quarter $(24 \%)$ of the 976,305 people who identified themselves as North American Indian, Métis or Inuit in 2001, reported that they had enough knowledge of an Aboriginal language to carry on a conversation (Statistics Canada, 2003). Place of residence is an additional census item that can potentially assist in estimation of population size, although again, it is not without its problems. For example, non-Aboriginal persons living in Aboriginal communities may be erroneously included as Aboriginal in population totals. Clearly any attempt at estimation using information on place of residence would have to introduce adjustments for this likelihood.

\section{Legal Recognition}

According to the 1982 Constitution Act of Canada (Royal Commission on Aboriginal Peoples, 1996), there are three major groups of Aboriginal Peoples in Canada: North American Indians, the Métis and the Inuit. Yet while legislation recognises these three broadly defined Aboriginal groups, it does not actually define what constitutes their populations.

The Indian Act of Canada is the main Canadian legislation which explicitly defines a specific subset of the North American Indian population: Status Indians, also referred to as registered Indians. This legal definition was initially developed in order to determine residency rights within reserves (The Canadian Encyclopaedia, 1987). The first post-Confederation version of the Indian Act dates back to 1876. Canada's Indian Act has undergone many revisions and 
iterations since the $19^{\text {th }}$ century (Savard and Proulx, 1982). By virtue of the Indian Act, registered Indians have certain specified entitlements, including the right to elect representatives to negotiate with the federal government over land claim settlements and other rights under treaties concluded with the Crown. According to the Census of Canada, the population who declared themselves to be Status Indian as defined by the Indian Act of Canada stood at 558,175 persons in 2001. The question used in the 2001 Census asked "Is this person a Treaty Indian or Registered Indian as defined by the Indian Act of Canada?"

There is a second valuable source of data available for the registered Indian population: the Indian Register. In 1951, the government of Canada established the Indian Register and assigned responsibility for its maintenance to the department of Indian and Northern Affairs (INAC). Only persons recognized as Indians pursuant to the Indian Act may be registered. This additional source estimates the population of registered Indians in Canada at 675,499 persons as of December 31, 2000 (INAC, 2002), 117,324 more than the 2001 Census conducted 5 months later. For the majority of individuals interested in Aboriginal issues, the existence of two significantly different estimates of the registered Indian population further complicates the issue of definitions. The difference between these two population estimates is an issue by itself that will be further discussed in the section on the quality of data.

Clearly the Indian Register is not available for non-status North American Indian population, nor is it available for the Métis and Inuit populations. With a few exceptions, the overwhelming majority of Status Indians are North American Indian in ancestry. The definitional challenges are subsequently far greater in moving on to the remainder of Canada's Aboriginal population. The obstacles to quantitative research climb when we shift our attention to the nonstatus North American Indian, Métis, and to a lesser extent, Inuit populations

\section{The Connection between Ancestry, Identity and Indian Status}

Intuitively, one could think that there is some sort of "hierarchical structure" to these three concepts of Aboriginality: the registered Indian population could be a subset of the Aboriginal identity population, which could be a subset of the broader Aboriginal origin population. Regardless of how convenient this view of the world might be, data reveal a more complex reality (Figure 2). The populations defined by these three concepts clearly overlap, but not completely. When brought together, the concepts of Aboriginal origin, Aboriginal identity and Indian registration define seven subsets of varying sizes. 
Table 2

Size and growth of the Registered Indian Population according to the Canadian Census and the Indian Register for Canada: 1996-2001

\begin{tabular}{cccc}
\hline $\begin{array}{c}\text { Registered } \\
\text { Indian }\end{array}$ & $\mathbf{1 9 9 6}$ & $\mathbf{2 0 0 1}$ & $\begin{array}{c}\text { Percent Change } \\
\mathbf{1 9 9 6 - 2 0 0 1}\end{array}$ \\
\hline Census & 448,000 & 558,000 & 14.3 \\
INAC $^{1}$ & 601,000 & 681,000 & 13.3 \\
\hline
\end{tabular}

1 These figures, as published by Statistics Canada are estimates of the Registered Indian population as based on the Indian Register as maintained by INAC. For both 1996 and 2001, these figures are rounded to the nearest 1000 and are meant to represent the size of the Registered Indian population on Census Day.

Source: Statistics Canada, 1998, 2003; Indian and North Affairs Canada, 1998.

The two largest subsets are made of (i) individuals who report an Aboriginal origin, an Aboriginal Identity and Indian registration (510,785) and (ii) individuals who report only an Aboriginal origin (441,395). The two other "unidimensional" subsets include (i) Aboriginal identity only and (ii) Indian legal status only, standing at 57,940 and 8,775 persons respectively. If we try to further improve this representation of Aboriginality by adding other dimensions such as First Nation/band membership (with or without), language or place of residence (in/out of an Aboriginal community), then the definition becomes almost unmanageable from an analytical perspective. It is in this context that demographers have endeavoured to document the demographic dynamics of Aboriginal peoples in Canada.

\section{Obstacles to Quantitative Research Data Quality Issues}

In the presentation of official statistics, the acknowledgement of imprecision in census data poses a task of considerable delicacy for statistical agencies. Official statistical agencies obviously need to protect their own reputation and credibility. In effect, some of the technical reports on the census give evidence of data quality problems. 
Charting the Growth of Canada's Aboriginal Populations:

Problems, Options and Implications

Figure 2. Three Dimensions of the Concept of Aboriginality, Canada, 2001

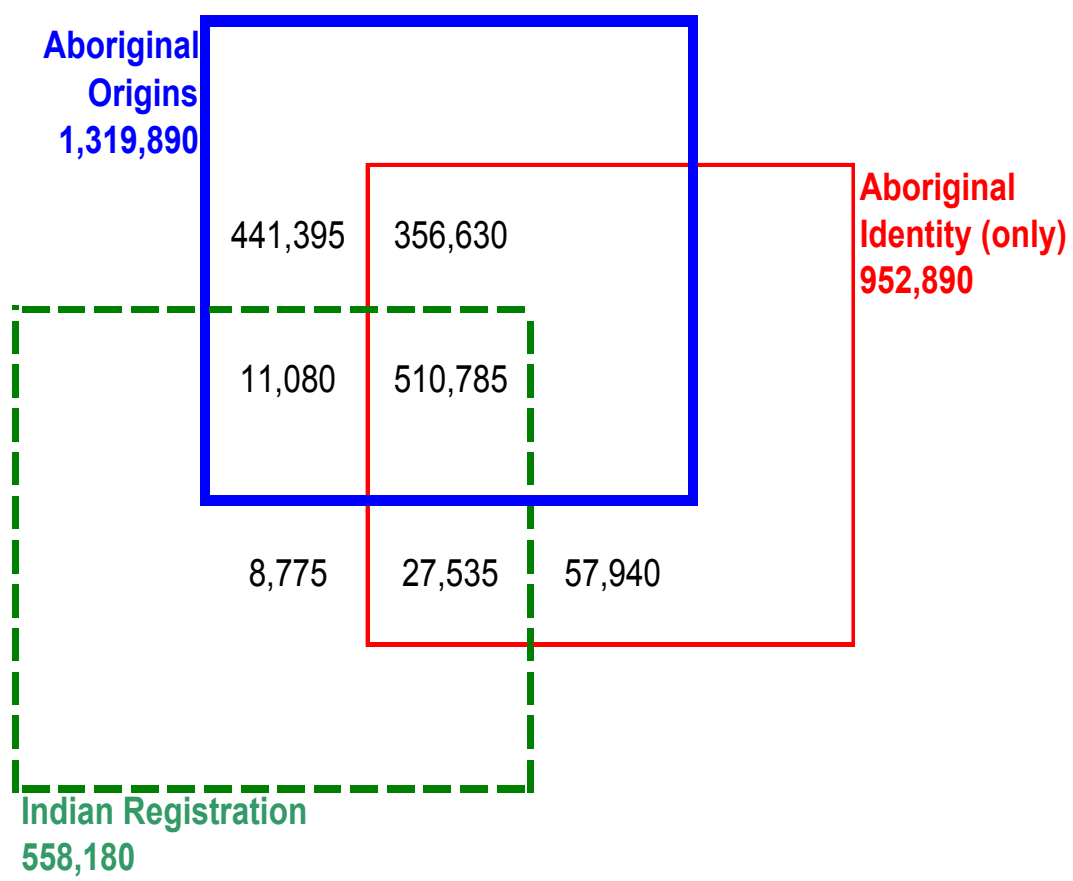

Source: Statistics Canada, 2001 Census of Canada, custom tabulations.

\section{Population Coverage}

In its official 2001 Census release on Canada's Aboriginal populations, Statistics Canada reported that a number of Indian communities refused to participate to the Census. As highlighted in the demographic profile of the Census release (Statistics Canada, 2003: 6), the enumeration was not permitted, or was interrupted before it could be completed, on 30 Indian reserves and settlements, largely for political reasons. In acknowledging this problem, an independent estimate of about 30,000 to 35,000 persons has been generated with respect to these non-participating reserves and communities. This estimate on population size was based on the most up to date census count available (prior to each reserve's refusal to participate in the census) along with an estimate of population growth as based on mathematical extrapolation techniques. The 
number of non-participating First Nation communities varies from one census to the next. Needless to say, this presents an additional problem with respect to data comparability. In the 1981 Census, 8 communities were incompletely enumerated. This number rose to 135 for the 1986 Census, fell to 78 and 77 respectively for the 1991 and 1996 censuses.

While Statistics Canada acknowledges this problem of community nonparticipation, it has never produced an overall estimate of a larger problem, i.e. the census undercount of Aboriginal populations, beyond this issue of nonparticipating reserves. The only information currently available relates to estimates generated with available census geography, or more specifically, for census subdivisions known as "Indian Reserves". The 1996 and 2001 Census coverage studies have indicated a population undercount of the order of $12-13 \%$ with regard to all persons living on Indian reserve, beyond the aforementioned reserves that refused to participate (Norris et al, 1995; Statistics Canada, 2003). To put this data quality issue into perspective, for the Canadian population overall, the extent of undercount has historically been of the range of $2-3 \%$ (Statistics Canada, 1999b). With regard to Aboriginal population living off reserve, there is no estimate of the level of undercount.

Is the enumerated Aboriginal population representative of the missed Aboriginal population? The working assumption has always been that it is representative, an assumption that may very well be flawed. Are the enumerated Aboriginal populations comparable over time? Again, the working assumption is that the available published data are comparable across censuses. Is the problem of census coverage error greater off reserve than on reserve, in Canada's cities or in rural areas? As it currently stands, it is only possible to speculate on the above issues.

\section{Inconsistencies between the Canadian Census and the Indian Register}

As previously indicated, over half a million Canadians $(558,175)$ reported being a registered Indian in the 2001 Census. This figure is noticeably lower than the official tally of 675,499 registered Indians as compiled by Indian and Northern Affairs Canada for December 31, 2000 (INAC, 2002). On the basis of this tally, Statistics Canada estimated that the total number for May $18^{\text {th }}$, 2001 (Census day) was around 681,000 (Statistics Canada, 2003). The true population likely falls somewhere between the INAC based figure of 681,000 and the direct census count at 558,175 . In taking a closer look at these published figures, the true population likely falls closer to the figure as based on the Indian register than on the census. 
Charting the Growth of Canada's Aboriginal Populations:

Problems, Options and Implications

Whereas Statistics Canada's figure is based on the 2001 Census, INAC relies upon a population register - commonly referred to as the Indian Register. While the census collects information by directly contacting and asking Canadians whether or not they are registered under the Indian Act, the Indian Register is in essence a list of all persons who have at one point or another been registered as a status Indian, and continue to be classified as such according to the Indian Act. Whereas the census is conducted once every five years, the Indian Register is updated on an ongoing basis - in documenting all new persons to be added to the register (predominantly through births) and all persons to be removed (through deaths).

Various factors are responsible for the discrepancy (Table 2) between these two estimates of the registered Indian population, including the fact that the 2001 Census was not permitted or was interrupted before it could be completed on 30 Indian reserves and settlements. In addition, the aforementioned problem of census undercount has also served to reduce the overall population count from the census (i.e. as both individuals and households are unintentionally missed in the census). Contrary to the Indian Register, the census is not capable of documenting registered Indians who, on Census day, are:

- Homeless;

- $\quad$ Living abroad (e.g., United States);

- Living in institutions or collectives included in the census (e.g., long-term care facilities, hospitals, federal/provincial correctional facilities).

A correction for all these factors would increase the census count of registered Indians, although certainly not account for all of this difference as observed.

There are also data quality issues with the Indian Register. Generally speaking, a register is effective only if it is systematically maintained and regularly updated through information on population changes, i.e., births, deaths, marriages and divorces. In the case of the Indian Register, however, individuals are not legally required to register events in a timely fashion. This results in frequent registration delays. Time series analysis of births by year of registration and by year of the event has shown that events have been registered as late as 18 years after the fact. An understatement in the registration of deaths could hypothetically lead to a slight overstatement of population size in the register. Specialists are well aware of this problem (Nault et al., 1993; Nault et al., 1992). 
Table 3.

Understanding Inconsistencies between the Canadian Census and the Indian Register

\begin{tabular}{|c|c|}
\hline $\begin{array}{l}\text { Census of Canada } \\
\text { Statistics Canada }\end{array}$ & $\begin{array}{c}\text { Indian Register } \\
\text { Indian and Northern Affairs Canada }\end{array}$ \\
\hline $\begin{array}{l}\text { - Large-scale survey of Canadian } \\
\text { population, which covers all } \\
\text { Aboriginal groups. Four questions } \\
\text { capture the notion of Aboriginality, } \\
\text { resulting in different counts } \\
\text { (Aboriginal origin, Aboriginal } \\
\text { identity, registered Indian, } \\
\text { Band/First Nation membership) }\end{array}$ & $\begin{array}{l}\text { - Administrative database containing } \\
\text { data on Status Indians only which is } \\
\text { updated regularly with information on } \\
\text { births and deaths }\end{array}$ \\
\hline $\begin{array}{l}\text { - Data available every } 5 \text { years (most } \\
\text { recent data available are for 2001) }\end{array}$ & - Data are available annually \\
\hline $\begin{array}{l}\text { - Provides demographic and socio- } \\
\text { economic information }\end{array}$ & $\begin{array}{l}\text { - Provides basic demographic } \\
\text { information (e.g., population size, age, } \\
\text { gender, geographic distribution) }\end{array}$ \\
\hline 2001 Census Population Counts & 2001 Indian Registry Population Count \\
\hline $\begin{array}{l}\text { Aboriginal Origin } \\
\text { Aboriginal Identity } \\
\text { Registered Indians } \\
\text { Band/FN Membership }\end{array}$ & $\begin{array}{l}\text { Registered Indians } \\
\left(681,000 \text { on Census day, May } 18^{\text {th }} \text {, }\right. \\
\text { 2001) }\end{array}$ \\
\hline $\begin{array}{l}\text { - In } 2001,30 \text { Indian reserves and } \\
\text { settlements did not participate in } \\
\text { the Census. }\end{array}$ & $\begin{array}{l}\text { - Late reporting of births and deaths can } \\
\text { result in inaccuracies. }\end{array}$ \\
\hline $\begin{array}{l}\text { - There is also some under-coverage } \\
\text { on participating communities and } \\
\text { an unknown amount of under- } \\
\text { coverage off-reserve. }\end{array}$ & $\begin{array}{l}\text { While the Census surveys only those } \\
\text { residents of Canada, the Indian } \\
\text { Register also includes Status Indians } \\
\text { living abroad. }\end{array}$ \\
\hline $\begin{array}{l}\text { - The Census does not identify the } \\
\text { ethnic affiliation of the population } \\
\text { living in institutions (e.g. prisons). }\end{array}$ & $\begin{array}{l}\text { - This register does not necessarily } \\
\text { record persons at their current place of } \\
\text { residence. }\end{array}$ \\
\hline
\end{tabular}


Charting the Growth of Canada's Aboriginal Populations:

Problems, Options and Implications

\section{Incomplete Data on Demographic Events}

Demographic analysis of Canada's Aboriginal population is seriously hindered by incomplete data on births, deaths and migration. The basic reason for this is that unlike in the United States, there are no ethnic or racial identifiers available in Canada's system of Vital Statistics. Whereas Canada's system of vital events is virtually $100 \%$ complete, it is currently not possible to delineate births and deaths by Aboriginal group, nor is it possible to turn to any other administrative data sets for information of comparable quality or comprehensiveness. For example, while the Indian Register is of reasonable quality, the information collected on births and deaths is limited to Status Indians - to the neglect of other Aboriginal Canadians. In addition, there is also a complete absence of direct information on the specific cause of death (fundamental to epidemiological research) nor is there information available on abortions or stillbirths.

As mentioned earlier, the Indian Register has two well-documented problems: late- and under-reporting of both births and deaths. In addition to late-reporting, certain events are never recorded in the Indian Register. For example, in the case of a child who dies before the recording of his or her birth, it is quite possible that both the birth and death will never be recorded in this register. Analysis of observed mortality by age has revealed abnormally low risks of death for children less than one year of age, but also for adults 65 years or older (Nault and George, 1992). In light of such acknowledged data quality problems, it is currently unknown as to what extent estimates of mortality (and life expectancy) might be misstated for registered Indians in Canada. If the Indian Register misses a significant number of deaths, estimates of life expectancy among Status Indians may in fact be seriously overstated. This is a somewhat disturbing observation given recent estimates of life expectancy that place Status Indians at about a six year disadvantage relative to other Canadians (Loh et al., 1998).

With regard to migration, the Indian Register is not particularly useful, as place of residence information is far from regularly updated, resulting in obvious difficulties in documenting migratory flows. Given the quality of this information, most estimates of migration for status Indians are currently based on the Canadian Census, using the question on place of residence 5 year ago. Since 1966, this item has been available on the census, such that an analysis of migration patterns of all Aboriginal groups is possible, yet again of uncertain quality. Problems here relate to the previously stated problems on coverage error - where difficulties in enumerating the Aboriginal population are compounded by difficulties in enumerating persons who change addresses between censuses. Whereas for the Canadian population overall, migratory 
flows are regularly estimated on the basis of federal tax files, this option is not available when narrowing one's focus toward the Aboriginal population.

\section{Difficulties in Establishing a Reliable Time Series}

\section{Population Growth}

While there are several alternate definitions relied upon in enacting quantitative research on Aboriginal peoples in Canada, on taking a closer look at the data, one can discern an interesting feature: regardless of the concept used in order to define Aboriginality, the Aboriginal populations experienced phenomenal growth during the 1980s and 1990s. Between 1986 and 2001, the Aboriginal origin, Aboriginal identity and registered Indian populations recorded relative fifteen-year increases of $80 \%$ to $110 \%$. By comparison, the total Canadian population increased by only $18 \%$ during the same period.

Looking specifically at the different Aboriginal identity populations, we observe differences in growth patterns (Figure 3). At the national level, for the registered Indian population which accounts for $57 \%$ of all Aboriginal populations in 2001, growth rates decline steadily between 1986 and 2001, from $6.4 \%$ to $2.8 \%$ per year. By contrast, the Métis population growth accelerated during this period, from $5.1 \%$ to $7.1 \%$ per year. Modest by comparison, the annual growth rates of the Inuit population remain almost three times higher than those of the Canadian population. Finally, the non-status Indian population, who display an erratic pattern of demographic growth, went from boom $(9.4 \%)$, to bust $(-7.7 \%)$ period, to rapid growth $(4.0 \%)$. It is possible that a large part of the bust for the nonstatus population involved a shift in how people identify in the census, from "non-status" Indian in 1991 to "Métis" in 1996. This is consistent with a substantial increase in the number of "Métis" over the 1991-1996 period.

Observed increases often exceed the maximum of $5.5 \%$ per year that is theoretically possible for a population that is subject only to the natural movement of births and deaths. For Canada's population overall, the average annual growth rates decreased from about $1.6 \%$ to about $0.8 \%$ over the intercensal periods. For the non-Aboriginal population, international migration played a larger role than natural increase in the growth over the most recent intercensal period. With the high rates of population growth in the Aboriginal population, there are also clearly phenomena other than fertility and mortality at work here. But what are they? 
Figure 3.

Average Annual Growth Rate (\%) of Aboriginal Identity Populations, Canada, 1986-2001

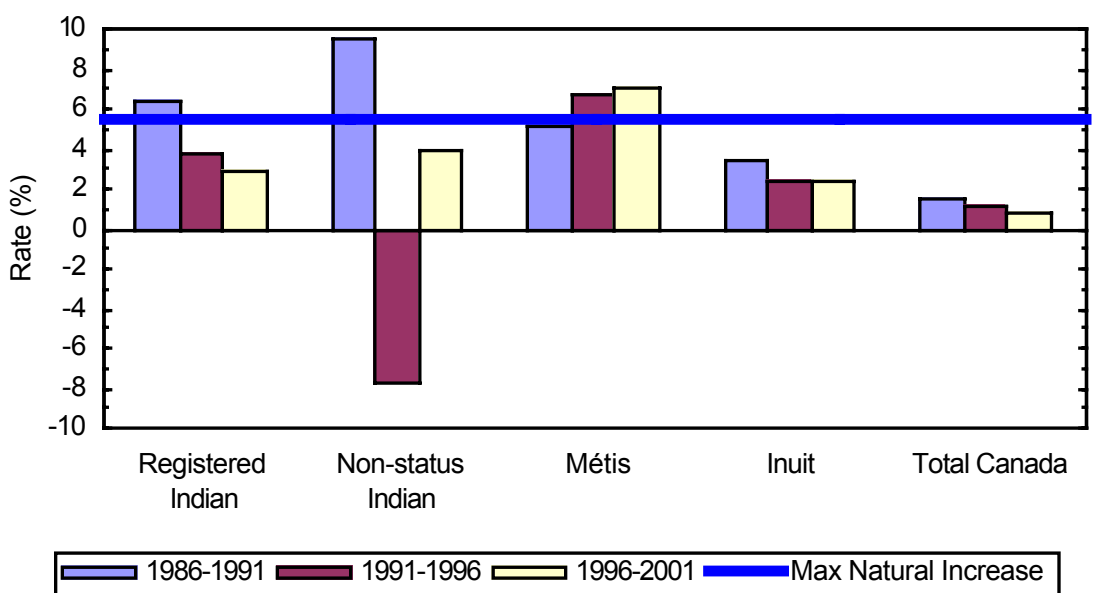

Note: The growth rates for the 1986-1991 and 1991-1996 periods have been adjusted for the non-participation of Indian communities.

Sources: Statistics Canada, 1986, 1996 and 2001 Censuses of Canada, custom tabulations.Statistics Canada, 1991 Aboriginal Peoples Survey, custom tabulations.

\section{Legislative Changes}

As aforementioned, the federal government has repeatedly introduced revisions to the Indian Act, which at times have had an appreciable impact on the size and growth of both the registered Indian and other Aboriginal populations. While many revisions have been introduced since its initial introduction in the $19^{\text {th }}$ century, the last legislative changes of any importance in this regard came with the introduction of Bill C-31 in 1985.

Prior to 1985, registered Indian women who out-married (i.e. to persons not entitled to Indian registration under the Indian Act) lost their Indian legal status, whereas registered men who out-married, not only retained their Indian status, but also transferred eligibility to their wives. With regard to births, patrilineal descent (or inheritance) was in place, such that only the offspring of registered Indian men would be entitled to Indian registration. Among registered Indian 
women, their offspring could obtain Indian status only if the father was also registered.

The 1985 Bill C-31 amendments to the Indian Act had the following three objectives:

- To restore the rights of individuals (and their children) who had lost their Indian legal status under earlier versions of the Indian Act;

- To remove discrimination from the Indian Act for the future by introducing new rules governing entitlement to Indian registration, such that entitlement was no longer defined on a patrilineal basis; and

- To provide the opportunity for individual First Nations to adopt their own rules governing eligibility for Indian band membership. This objective is not treated in this paper.

Quite significant demographic impacts are associated with the achievement of each of these objectives. Changes introduced by Bill C-31 affect not only the registered Indian population, but other Aboriginal populations, as well.

At the end of year 2000 (December $31^{\text {st }}$ ), a total of 114,512 individuals had (re)acquired registration under the provisions of Bill C-31, with most registrations occurring during the 1985-1995 period (88\%). As most of those who could potentially qualify for reinstatement have now done so, the number of potential new reinstatements has declined considerably. Between 1998 and 2000 , the average number of reinstatements reached only 2,310, less than a quarter the average observed during the initial ten year period (INAC, 2002). In addition to the reinstatements, Clatworthy (2003) has estimated that about 60,000 births would not have qualified for Indian registration under the rules of the "Old Indian Act". Overall, Bill C-31's changes to the Indian Act have resulted in incremental growth of about 174,500 individuals in the Indian Register, generating a population increase of nearly 35\% (Clatworthy, 2003).

\section{Changes in Self-Reporting of Aboriginality}

The exceptional growth of other Aboriginal groups, i.e. the non-status Indians, the Métis and the Inuit, observed during the 1986-2001 period can not be explained by the Bill C-31 factor. If any, the Bill C-31 factor should have had a negative impact on the demographic growth of these other Aboriginal groups. This may be the reason for the decline in the number of non-status Indians over the 1991-1996 intercensal period (Figure 3). Analysis has shown that observed growth exceeds by far the expected growth due to natural increase (births minus deaths), even after the data quality variations and the legislative changes have 
been factored in the analysis. For the 1996-2001 period, Statistics Canada recognizes that "increased awareness of one's Aboriginal roots likely accounted for another half (of the observed population growth), as more people identified themselves as Aboriginal" (Statistics Canada, 2003).

Figure 4

Registered Indians who where registered based upon 1985 Bill C-31 amendments to the Indian Act, 1985-2000

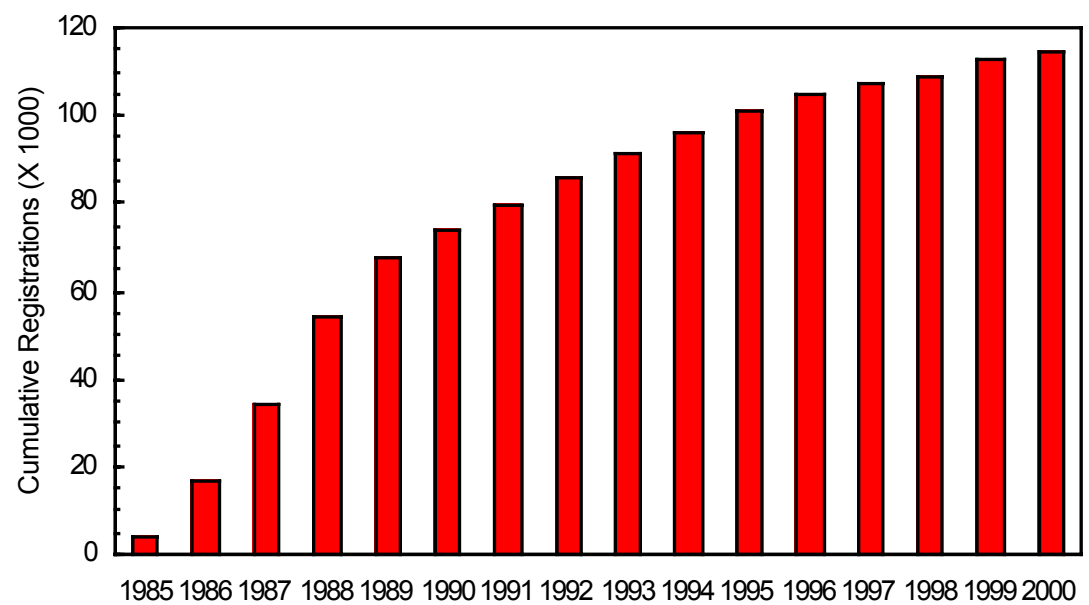

Source: INAC (2002).

Note: These figures exclude the aforementioned births, as estimated by Clathworthy (2003).

Aboriginal populations of the United States (Passel, 1997), Australia (Ross, 1996) and New Zealand (Pool, 1991) have also experienced rapid demographic growth during the $80 \mathrm{~s}$ and 90 s largely driven by shifts in self-reporting of Aboriginality. There is no definitive answer to explain these shifts, beyond the fact that it is extremely difficult to establish fixed identities and stable boundaries in the delineation of ethnic or cultural groups (Eschbach, 1995; Hout and Goldstein, 1994; Lieberson and Waters, 1988). After documenting a similar situation in the United States among American Indians, Passel (1997) makes reference to a whole series of societal changes that may very well have influenced the propensity on the part of Americans to report American Indian heritage. Of particular importance in this context was a new sense of political 
awareness and self-confidence, which has contributed to a raising of North American Indian consciousness in certain individuals who had heretofore not identified with this culture.

In the Canadian context, it is similarly possible to speculate on several predisposing factors that may very well enter into explaining this growth. For example, Canada's multicultural character is certainly relevant, as people from different ethnocultural backgrounds meet, marry and have children. These children, with their mixed ethnocultural background, have the possibility of choosing/switching their ethnic identity, and many will do so according to the situation. Socio-political events and their media coverage have served to heighten the awareness of the public and, most importantly, to restore the image and pride of Aboriginal Peoples. Furthermore, the present legal context in Canada could favour even more "ethnic drifting" into Aboriginal groups, particularly from mixed ancestry persons. The central element here is the notion of benefits, real or perceived, attached to Aboriginal affiliation.

\section{Concluding Thoughts and Recommendations}

In reading the above, it might be argued that we have portrayed a rather bleak picture of the state of demographic data and quantitative research on Aboriginal populations in Canada. What is clear is that some issues can and have been addressed, while others remain uncharted. What is certain from this brief review is that demographic research on Aboriginal peoples in Canada is far from straight forward. Competing definitions yield different population counts. It is not perfectly clear where "Aboriginal boundaries" stand presently, nor how these boundaries have changed over time.

In light of the legislative and self-identification changes, interpreting change in the demographic and socio-economic characteristics of this population is extremely difficult. While the federal government has a clear definition of who is "Indian in a legal sense" (i.e. Status Indian), it is argued that beyond this definition there is no dominant definition for the remainder of Canada's Aboriginal population. There are at least two primary reasons for this situation, including (i) the concept of ethnicity (and Aboriginality) is far from straight forward, and has been quite variable over time, and (ii) there are currently several stakeholders (often with competing interests) that are very much concerned with how this population is delineated. Both federal and provincial governments are very much interested in this issue, as are Aboriginal political organisations and private interests. Consequently, much demographic research on the Aboriginal population is conducted in a highly politicized environment. 
In this context, several questions surface. First, is it reasonable (or even desirable) to expect that we can rely on a single and unique definition of the Aboriginal population? Given the fluid nature of the concept of ethnicity, it might be argued that searching for a universal definition in this context is neither useful nor realistic. Any definition must be consistent with a specific objective (be they academic or applied in nature). If political and legal issues are of priority, then a legal criterion might be emphasized (i.e. who exactly is registered under the Indian Act). If the main objective of research is to distinguish various ethno-cultural groups, then First Nations membership might be emphasized. Presently, for policy and social planning purposes, federal departments typically use some sort of blended "identity/ registration/ First Nations membership" definition. Depending upon the specific policy and social planning purposes, the authors believe that this may very well be the most appropriate trade-off for those who are engaged in policy research and/or interested in the administration of government programs.

Regardless of these issues, there are clearly major obstacles in documenting the relative social and economic conditions of Aboriginal peoples, relative to other Canadians, and especially in terms of determining whether or not meaningful progress has been made over the last decades. Although time series data are currently available (as for example via the Canadian Census), it is obvious that the temporal reliability of such data is low. In addition, this time series of census data is obviously not a true longitudinal dataset, allowing us to identify the exact same persons or subpopulations defined in terms of ethnicity over time. While this lack of reliability hinders both social research and public planning, there are currently various alternatives that theoretically could be implemented, in improving upon the utility of quantitative data available. Of particular promise in this regard is the possibility of direct record linkage procedures, as for example, it is technically possible to directly link individual records from the 1996 census to those from the 2001 census or the 1991 Census. Similarly, it is technically possible to link records from the Indian Register to the Canadian Census and/or to Vital Statistics, in better documenting the socioeconomic and demographic dynamics experienced by First Nations peoples in Canada.

Currently Health Canada, is open to the idea of linking the Indian Register to other data sources (e.g. Census, Medical Records, Vital Statistics), given the potential for an major gains in terms of relevant data, with limited cost with no increase in response burden for Canada's First nations (Probert, 2003). From a strictly demographic standpoint, a reliance upon record linkage procedures is clearly a preferred option in this context, given the limitations of indirect estimation techniques and the enormous costs involved in gathering information that is already, theoretically available, by merely linking records. Not only 
would this help in making quality estimates of fertility and mortality, but it would also improve population estimates, in partly by helping to address the issue of census coverage error. Statistics Canada is currently opposed to this option of direct data linkage, in principal, due to concerns regarding privacy and fear of negative reaction to future Census activities. As these are very real concerns, Statistics Canada might be advised to further explore this possibility, while continuing its long tradition of consulting with interested stakeholders including Aboriginal organizations and communities.

It is the opinion of the authors that this issue should be revisited, given the potential gains in knowledge. Statistics Canada itself could oversee all of this research with its own employees and under its own security. Statistics Canada already carries out activities which involve linking consecutive censuses, as for example, in the context of census coverage evaluation studies (i.e. the Reverse Record Check). Under its own supervision, no threats exist currently as to the privacy of individual Canadians with this type of data linkage. Analyses of this type could potentially improve, by a substantial degree (i) our understanding the demographic dynamics of this population (ii) the quality of quantitative research on the social economic conditions of Aboriginal peoples, and (iii) the quality of information on the state of population health of Canada's First Nations.

On a limited scale, the province of Manitoba has already initiated collaborative research with Indian and Northern Affairs in an effort to exploit such data linkage techniques (O'Neil and Martens, 2002). In addition, the British Columbia Vital Statistics Agency has partnered with the First Nations and Inuit Health Branch of Health Canada to provide population estimates and health statistics for Status Indians in British Columbia since 1989, directly involving the use of record linkage procedures (Soo-Hong Uh, 2002). Similar research, while switching the emphasis to consecutive censuses, can potentially assist researchers in understanding the impact of legislative and self-identification changes on the characteristics of Canada's Aboriginal population. Such analyses are invaluable tools for evaluating a posteriori the demographic implications of programs, policies and legislation designed to improve the social and economic conditions of Aboriginal peoples. These collaborative efforts should now include Statistics Canada.

In the absence of reliable time series, there are serious difficulties in planning for the future. For the Canadian population overall, demographic forecasts have considerable utility in preparing for future health care needs, housing requirements, social security, educational planning, and a variety of other public services. In the context of Aboriginal peoples, an absence of quality information on the past leaves for an absence of reliable forecasts in planning for the future, even over the shorter term. What data do we use for fertility and mortality? To 
Charting the Growth of Canada's Aboriginal Populations:

Problems, Options and Implications

what extent can we expect further shifts in the reporting of Aboriginal identity or ancestry? In the current context, an absence of quality time series makes it very difficult to project the population into the future.

Demographers produce population estimates/projections to answer the question of how many. Policy and program analysts rely on these projections to answer the question of "how much". If present demographic models cannot accurately say "how many", how can policy analysts effectively determine program costs? With this in mind, efforts by both academic researchers and government agencies to involve Aboriginal peoples and organizations in the resolution of many of these conceptual issues continues to be important. As many of the issues as raised in the current paper are the result of vested political interests, the ongoing participation of all interested stakeholders in discussions relating to demographic research may very well serve to "depoliticize" the data collection process in Canada, and improve upon the quality of available data for policy and academic work.

\section{End Notes:}

1. On-reserve population is a derived census variable that is captured by using the Census Subdivision (CSD) type according to criteria established by Indian and Northern Affairs Canada (INAC). The following CSD types are based on the legal definition of communities affiliated with First Nations or Indian Bands: Indian Reserve (R), Indian Settlement (S-E), Indian Government District (IGD), Terres réservées (TR), Nisga'a Village (NVL), Nisga'a Land (NL) and Teslin Land (TL) (Statistics Canada, 2002).

\section{References:}

Boxhill, W, 1984. Limitations of the Use of Ethnic Origin Data to Quantify Visible Minorities in Canada. Working paper prepared for Housing, Family and Social Statistics Division, Statistics Canada.

Boyd, M. and D. Norris, 1999. "Canadian Eh? Ethnic Origin Shifts in the Canadian Census" Canadian Ethnic Studies 31: 1-19.

Chackiel, Juan and Peyser Alexia, 1993. Indigenous Population From Latin American National Censuses. Paper presented at the Population Conference. Montreal: International Union for Scientific Study of Population. 
Clathworthy, Stewart J, 2003. "Re-accessing the Population Impacts of Bill C31 Section 6." in Aboriginal Conditions: Research Foundations for Public Policy, edited by J. White, P. Maxim and D. Beavon, Vancouver: University of British Columbia Press.

Demers, Linda, 1979. Évaluation de la qualité des informations ethniques et linguistiques fournies par les recensements canadiens, de 1901 à 1976. Université de Montréal, Mémoire de maîtrise en démographie, 147 pages

Dickason, Olive. 2002. Canada's First Nations: A History of Founding Peoples from Earliest Times. Toronto: Oxford University Press.

Eschbach, Karl, 1995. "The Enduring and Vanishing American Indian: American Indian Population Growth and Intermarriage in 1990." Ethnic and Racial Studies 18: 89-108.

Eschbach, Karl, 1993. "Changing Identification among American Indians and Alaska Natives", Demography, 30(4): 635-652.

Frideres, James S, 1998. Aboriginal Peoples in Canada: Contemporary Conflicts. Scarborough: Prentice Hall Allyn and Bacon Canada.

Globe and Mail. January 22, 2003. "Growth for Canada's First Nations"

Goldmann, Gustave, 1993. The Aboriginal Population and the Census. 120 Years of Information -1871 to 1991. Paper presented at the Conference of the International Union for the Scientific Study of Population (IUSSP), Montréal.

Goldmann, Gustave, 1998. "Shifts in Ethnic Origins Among the Offspring of Immigrants: Is Ethnic Mobility a Measurable Phenomenon?" Canadian Ethnic Studies 30: 121-148.

Guimond, Eric, 1999. "Ethnic Mobility and the Demographic Growth of Canada's Aboriginal Populations from 1986 to 1996." in Report on the Demographic Situation in Canada 1998-1999, edited by Alain Bélanger. Ottawa: Statistics Canada. Catalogue no. 91-209. Pp. 187-200.

Guimond, Eric, 2003. "Changing Ethnicity: The Concept of Ethnic Drifters", in Aboriginal Conditions: Research Foundations for Public Policy, edited by J. White, P. Maxim and D. Beavon, Vancouver: University of British Columbia Press. 
Charting the Growth of Canada's Aboriginal Populations:

Problems, Options and Implications

Hout, Michael and Joshua Goldstein, 1994. "How 4.5 Million Irish Immigrants Became 40 Million Irish Americans: Demographic and Subjective Aspects of Ethnic Composition of White Americans." American Sociological Review 59: 64-82.

INAC, 1998. Registered Indian Population by Sex and Residence 1997. Ottawa: Department of Indian Affairs and Northern Development. Catalogue no. R31-3/1997.

INAC, 1999. A Second Diagnostic on the Health of First Nations and Inuit People in Canada. Ottawa: Department of Indian and Northern Affairs Canada.

INAC, 2000. Registered Indian Population Projections for Canada and Regions, 1998-2008. Ottawa: Department of Indian and Northern Affairs Canada.

INAC, 2002. Basic Departmental Data. Ottawa.

Kralt, John, 1990. "Ethnic Origin in the Canadian Census, 1871-1986" in Ethnic Demography: Canadian Immigrant, Racial and Cultural Variations, edited by S.S.Halli et al., Carleton Library Press. Pp. 12-29.

Krotki, Karol J, 1995. "The Eight Million Artificial Canadians, their Future and Related Policies" in Toward the XXIst Century: Emerging SocioDemographic Trends and Policy Issues in Canada. Ottawa:

Proceedings of the 1995 Symposium organized by the Federation of Canadian Demographers.

Lieberson, Stanley and Mary C. Waters, 1993. "The Ethnic Responses of Whites: What Causes Their Instability, Simplification, and Inconsistency?" Social Forces 72: 421-450.

Lieberson, Stanley and Mary C. Waters, 1988. From Many Strands: Ethnic and Racial Groups in Contemporary America. New York: Russel Sage Foundation.

Loh, Shirley, 1990. Population Projections of Registered Indians, 19862011. Report prepared by Population Projections Section, Demography Division, Statistic Canada for Indian and Northern Affairs Canada.

Loh, Shirley, 1995. Projections of Canada's Population with Aboriginal Ancestry, 1991-2016. Report prepared by Population Projections 
Section, Demography Division for Employment Equity Data Program, Housing, Family and Social Statistics Division, Statistics Canada.

Loh, Shirley, Ravi Verma, Edward Ng, Mary Jane Norris, M.V. George and Jeanine Perreault (1998). Population Projections of Registered Indians, 1996-2021. Report prepared by Population Projections Section, Demography Division, Statistics Canada for Indian and Northern Affairs Canada.

Nault, François, Jiajian Chen, M.V. George and Mary Jane Norris, 1993.

Projections de la population indienne inscrite, 1991-2015. Ottawa :

Affaires Indiennes et du Nord Canada, Direction générale de la gestion de l'information et de l'analyse, groupe Analyse quantitative et recherche socio_démographique, 199 pages.

Nault, François, Jiajian Chen and Mary Jane Norris, 1992. Demographic Time Series Data on Births, Deaths and population for Registered Indian Population, Canada, 1973-1990. Ottawa: Statistics Canada, Demography Division, Report prepared for Indian and Northern Affairs Canada.

Nault, François and Eric Jenkins, 1993. Projections of Population with Aboriginal Ancestry Canada, Provinces/Regions and Territories, 1991-2016. Housing, Family and Social Statistics. Ottawa: Statistics Canada, catalogue no. 91-539-XPE

Nault, François and M.V. George, 1992. New Estimates of the Mortality of Registered Indians, Canada, 1973-1990. Paper presented at the 1992 annual meeting of the Canadian Population Society, Charlottetown, Canada.

Norris, Mary Jane, Stewart Clatworthy and Eric Guimond, 2001. Demography, Legislation and Ethnic Mobility: Considerations and Implications for Projections of Canada's Aboriginal Populations. Paper presented at the Annual Meeting of the Population Association of America (PAA), Washington.

Norris, Mary Jane, Don Kerr and François Nault, 1995. Projections of the Population with Aboriginal Identity in Canada, 1991-2016. Ottawa: Statistics Canada, Demography Division, Population Projections Section, report prepared for the Royal Commission on Aboriginal Peoples, 101 pages. 
Charting the Growth of Canada's Aboriginal Populations:

Problems, Options and Implications

O'Neil, John and Patricia Martens, 2002. The Health and Health Care Use of Registered First Nations People Living in Manitoba: a PopulationBased Study. Paper presented at the Aboriginal Policy Research Conference. Ottawa, Ontario.

Passel, Jeffrey, 1997. "The Growing American Indian Population: 1960-1990: Beyond Demography." Population Research and Policy Review 16: 11-31.

Perreault, Jeanine, Lyne Paquette and M.V. George, 1985. Population Projections of Registered Indians, 1982-1996. Report prepared by the Population Projections Section, Demography Division, Statistics Canada for Indian and Northern Affairs.

Pool, Ian, 1991. Te Iwi Maori: A New Zealand population past, present and projected. New Zealand. Auckland. Auckland University Press.

Probert, A. 2003 "Linking Health Records" Health Policy Research 5: 30-31.

Ponting, Rick J, 1997. First Nations in Canada: Perspectives on Opportunity, Empowerment, and Self-Determination. Toronto: McGraw-Hill Ryerson.

Robitaille Norbert and Robert Choinière (1987). "L'accroissement démographique des groupes autochtones du Canada au XXe siècle", Cahiers Québécois de démographie $16: 1$.

Robitaille, Norbert and Eric Guimond, 2001. The Reproduction of Aboriginal Groups: Exogamy, Fertility and Ethnic Mobility. Paper presented at the Conference of the International Union for the Scientific Study of Population (IUSSP), Brazil.

Romaniuc, Anatole, 2000. "Aboriginal Population of Canada: Growth Dynamics Under Conditions of Encounter of Civilisations." The Canadian Journal of Native Studies 20: 95-137.

Ross, Kate, 1996. Population Issues, Indigenous Australians. Australian Bureau of Statistics. Occasional Paper 4708.0. 88 pages.

Royal Commission on Aboriginal Peoples, 1996. Final Report of the Royal Commission on Aboriginal Peoples. Ottawa, Ontario.

Ryder, Norman 1955. The Interpretation of Origin Statistics. Canadian Journal of Economics and Political Science 21: 466-479 
Eric Guimond, Don Kerr and Roderic Beaujot

Siggner, Andrew J. and Gustave Goldmann, 1995. Statistical Concepts of Aboriginal People and Factors Affecting the Counts in the Census and the Aboriginal Peoples Survey. in Toward the XXIst Century: Emerging Socio-Demographic Trends and Policy Issues in Canada. Ottawa: Proceedings of the 1995 Symposium organized by the Federation of Canadian Demographers.

Soo-Hong, 2002. Regional Analysis of Health Statistics for Status Indians in British Columba, 1991-2001. Paper presented at the Aboriginal Policy Research Conference. Ottawa, Ontario.

Statistics Canada, 1998. 1996 Census: Aboriginal Data, in The Daily, January 13,1998

Statistics Canada, 1999a. 1996 Census Dictionary. Ottawa: Statistics Canada, Final Edition Reference, catalogue \#92-351-UIE.

Statistics Canada, 1999b. Coverage. 1996 Census Technical Report. Ottawa: Statistics Canada, catalogue \#92-370-XIE.

Statistics Canada, 2002. 2001 Census Dictionary. Ottawa: Statistics Canada, Census Operation Division, catalogue \#92-378-XIE.

Statistics Canada, 2003. Aboriginal peoples of Canada: A demographic profile. Ottawa: Statistics Canada, 2001 Census analysis series, catalogue \# 96F0030XIE2001007.

White, Pamela M., Jane Badets and Viviane Renaud, 1993. "Measuring Ethnicity in Canadian Censuses", in Challenges of Measuring an Ethnic World. Science, Politics and Reality, edited by Statistics Canada and U.S. Bureau of the Census, Proceedings of the joint Canada-United States Conference on the Measurement of Ethnicity, 223-269. 